\title{
The design and application of heterogeneous isomorphism traditional batik pattern
}

\author{
Xiong Huan ${ }^{1, a}$ \\ ${ }^{1}$ Jiangxi Institute of Fashion Technology, Jiangxi, Nanchang, 330201 \\ a447082226@qq.com
}

Keywords: Heterogeneous isomorphism. Wax printing; Pattern design; application

\begin{abstract}
In collecting on the basis of traditional batiks patterns, the traditional batiks patterns are classified and summarized the composition of traditional batiks patterns in the form of law, law of color, pattern characteristics, cultural connotation, refining traditional batik pattern elements, will be the relationship between defamiliarization context design, in the traditional ethnic culture unique language to create a new pattern, and applied to bags, shoes, umbrella, articles such as tableware, T-shirt design, make the design work of the formation of strong Chinese flavor and modern fashion, arouse people's unique feelings to familiar, strengthen the design works of aesthetic temperament and interest.
\end{abstract}

\section{Heterogeneous isomorphism theory and art design}

Heterogeneous isomorphism theory put forward by the gestalt psychologist, said: as the object of attention object always has a certain physical structure, these structure presents a physical structure of the force field respectively, and the object of physical tension structure, bioelectricity force field in the brain, the perceptual field occurs in the process of psychological activity corresponds to, the relationship between phase induction, this relationship is called a heterogeneous isomorphism.

Arne haim exploit this heterogeneous isomorphism theory to explain the formation of aesthetic experience, thought: the external things, art style, people's perceptual organization activities as well as the relationship between the fundamental unity within, they are a model, the action of forces and once the action of forces in the field of this a few patterns to achieve consistent (heterogeneous isomorphism) on the structure, can arouse the aesthetic experience. Heterogeneous isomorphism theory in aesthetic, aesthetic empathy, lenovo synaesthesia and metaphor are put forward its own opinions. In terms of aesthetic metaphor, arne haim advocates note they seek and performance between different things equal points, through the shell of things, will be the basic style is the same, in addition to the force of the rest all have little in common with different things together. In the field of art and design, heterogeneous isomorphism is a form of surrealism, is a clever combination of two or more elements together, form a new form, new creative value and is showing.

\section{Heterogeneous isomorphism theory the feasibility of using traditional batiks patterns}

Traditional batik design theme is mainly derived from the natural environment in the object of imitation as well as to the records of profound national culture and expression, which can be roughly divided into geometric pattern, portrait, animal patterns, plant designs and gods, various forms and colorful. Traditional batiks patterns with strong ethnic characteristics, expressive features unique charm, has a unique decorative effect and the infinite artistic vitality, at the same time have the double function of decoration and ideographic, load a lot of good wishes of exorcism is auspicious, ideal, moral, history and legends. In the face of contemporary Chinese nationality folk traditional hand-made batik art and the culture, how to inheritance and innovation is a scholars in the long-term exploration, but opinions vary. Will use traditional batik design heterogeneous isomorphism theory, break through the conventional context of Chinese traditional batiks patterns, its product design and other design elements clever docking, try with a new Angle of view to re-examine the traditional batik design, make its and modern personality aesthetic demand better, and the integration of contemporary fashion, with new vitality. 


\section{The traditional design method of wax pattern of heterogeneous isomorphism}

Colour modelling refactoring. Traditional design color batiks is mostly the blue and white of of primitive simplicity, although there is a blue and white porcelain, elegant beauty, but, after all, a single application scope is limited. The author of the modelling of traditional batiks patterns from the combination of dot, line, face, the contour and the silhouette of the refactoring, morphological characteristics, in the shape of a performance object, and on the basis of the basic accord with natural animal form appropriate local characteristics, make its image breezy and rich decorative, then change the colour of traditional batik, will introduce a popular color pattern design, so that is suitable for the whole style and modelling design carrier.

Vortex lines is the typical patterns of miao batiks, are used in a lot of branch of miao nationality costumes, basic regular use in women's clothing, backpack, sleeves. Vortex lines form the origin of a variety of, once a miao thirteen years, important ancestor worship activity brighter hidden section to sacrifice to the cow, tauren have spin can be selected at the top of a vortex form a symbol of the ancestors; Secondly, think "vortex form" is the pattern of the early ancestors created, adopt lineage is respect for ancestors, can get ancestors protection; A third is duly concluded that vortex is composed of the totem sign of primitive bird lines evolution is a tribal marks. The author collected from traditional batik pattern basic morphology and structure of "excitement" arrange them, cut for the quality of the appeal itself meaningless into continuous gradient form, pay attention to the overall context modelling contrast and unity relations form, seeking duly vortex lines between each element and design the context of the shape, location, the inner link and common characteristics such as color, texture, around the theme and the foil to join an element in common tendency, shape, size, location, or the color integration of assimilation, give a person neat feeling and sense of order, make the design produce harmonious beauty.

The use of technology method. Through traditional batik wax knife or pen, dip, wax-melting painted design on the cloth, after impregnation to wax and form graphics; Usually in two-dimensional space, the heterogeneous isomorphism is the integration of modern forms, craft technique, design language and the internal relations of different elements, using embroidery, lace, splicing, patched up, bend and fold, accumulation, hollow out technology combined with abundant material break traditional conventional thinking to form a new form of creative, change the wax pattern conventional spatial relationships, subversion narrow perspective plane design, realization of wax pattern stereo effect, creating interesting visual form; Make traditional batik design elements and other fancy element perfect fusion, and even get better visual effect.

(1) play seed embroidery, embroidery embroidery, beads embroidery, embroidery and other techniques, to stitch structure pattern, decorative fabric of different stitches of batiks are distinctive design; Cantonese embroidery unique traditional techniques of gold and silver thread embroidery is also called the nail gold embroidery, gold embroidery with gold and silver line is adopted, with floating cushion, design a stereo anaglyph effect, smooth and beautiful.

In the design, hand embroidery also can be used in a relatively low cost, high efficiency, strong practicability machine needlework; Supplemented by set auger, printing process, such as good decorative effect; For large-scale assembly line production, in the casual shoes market, at the same time can hand embroidery technology and the traditional batik design culture, heritage and generation.

(2) lace is characterized by mesh, its pattern design pays attention to the density. Batiks patterns through long-term tactile experience has formed the inherent understanding, which is predominantly tabby fabric texture is presented in the visual, traditional batiks patterns by bud silk as material performance can make the pattern produces special three-dimensional texture, change the conventional two-dimensional spatial relationships, upset the plane design of narrow perspective create interesting visual form.

More iconic flowers, animals, portraits and totem pattern; And there is no limit to the lace process of wax printing designs, go machine embroidery needle change in the form of dot, line, surface decoration. Its modelling concise pure language, used to represent the traditional batik pattern is a kind of novel and delicate way. 
In the bud silk chiffon dress skirt, in the design of the whole garment body design adopts is given priority to with nylon, spandex elastic fabrics frivolous lace, contracted and not simple decoration; The material selection of smooth soft silk spun silk spinning. Lace patterns drawn from the tradition of a complete huang miao batiks patterns, the author tries to break the traditional batik design original visual form and the viewer's mind-set, will grace the nature with wax pattern forms constitute an organic fusion, change the color of the original wax pattern looks, create the formal beauty of other traditional batik pattern. Comfortable soft lace through clever design can make up for the inadequacy of the human body, make the wearer look more beautiful, do not have lasting appeal one time after dressing; Different material of two kinds of fabric on the body naturally formed the actual overlap, the wearer can show in walk graceful posture.

(3) the quilting is between the two pieces of cloth after joining fillers in accordance with the packing designs made open wire, relief as the visual effects, reflect effect by filling in the core material, should be chosen after the core filling material can reflect the effect of design. In the process of sewing, according to the change characteristics of wax pattern suitable for quilting method, the patterns of the seam line for easy use English quilting, rope line pattern or area with Italian quilting, the quilting process of wax printing design choose Italy quilting is advisable.

Bag bag design, the first thing you need to clear the package bag overall design positioning, content and style of traditional batik designs with cotton and linen material between the shape, position, color, texture and other internal relation and common characteristics, foil to join the pure manual suture, wooden buttons around the simple rustic environmental ecological theme tend to produce together, make the bag bag style harmonious and unified whole; On the canvas, linen material USES different color stitching, through the quilting process to simplify the guizhou traditional batik pattern heterogeneous tile decoration, let the user in the process of suspender found after traditional batik heterogeneous combination of surprise again. Besides with the help of yan sewing process of wax printing design, also can use process simpler embossing process, need to order in the sewing process, to ensure that no overlapping destruction complete traditional batiks patterns.

\section{Conclusion}

The production of modern design products, is no longer only for the material production of product, and more diversified, multi-level to mass culture needs and aesthetic pursuit and creation. Hermes scarves, bags design are popular with people around the world, the key lies in its continuous absorption and innovation in the design of the traditional elements; Lott, nigel resistant film animation is also influenced by the Chinese shadow play and paper-cut; Domestic ladies "providence administered with traditional design elements with ink and wash, make the brand clothing in ecological, healthy, peaceful and beautiful. Thus, abandon those blind adherence style or stubborn attitude can derive a new art form.

All nationalities in Chinese traditional batiks patterns is the long-term labor accumulation of life to create a design with the form of auspicious implies perfect combination, has rich implication and profound philosophic theory, was later generations inherit and spread extensively, it contains the design of various laws of beauty invisible became the design of a new place. Traditional batiks patterns with characteristics of typical symbols can homogeneous heterogeneous isomorphism design to gain new vitality, in this way, the classic of traditional culture, and make it and the integration of contemporary fashion, show the means and the sense of rhythm and the rhythm of modern life, designed with modern and do not break the pattern of the ethnic flavor, make traditional batiks patterns and modern personality aesthetic demand better.

\section{Reference}

[1] Jiang Yali; Avi zhang; Jose wang jun. Heterogeneous isomorphism theory application in the design of Chinese traditional culture study [J] horizon of science and technology, 2015 (18) : 3637. 
[2] Yu Jiping; James tien. Miao miao batiks patterns look simple aesthetic pursuit of [J] art research, 2011 (04) : 56-57.

[3] Yang Yuan. Heaven and earth, ancestors, ghosts and gods: religious spirit of the guizhou minorities research [J], $2000(02)$ : 84-86.

[4] Jiang Xiaoyun. 'view of inheritance and development of anshun batik under the study [J] journal of guizhou university (art), 2011 (01) : 96-98. 